\title{
El Domo de la Roca: la ideología tras el símbolo
}

\author{
The Dome of the Rock: \\ Ideology beneath the Symbol
}

\section{FERNANDO CISNEROS*}

Resumen: El Domo de la Roca —en árabe Qubbat al-Sakhra- es el monumento del arte islámico al que se le han dedicado más estudios en años recientes. En el presente artículo se parte del valor de su emplazamiento, dado que el lugar en el que se encuentra erigido representa por sí mismo una referencia simbólica, a la vez que puede estudiarse tanto desde el punto de vista de su aspecto material, al tratarse de una obra de arte, como de su significado para diferentes grupos sociales y distintas épocas, dentro del concepto de "dominio de memoria" enunciado por Foucault.

Palabras clave: Domo de la Roca; santuario semítico; templo judaico; Jerusalén cristiana; conquista musulmana de Palestina.

Abstract: The Dome of the Rock -Qubbat al-Sakhra in Arabic- represents the monument of Islamic art which in recent years has been the subject of the most studies. The present article emphasizes the significance of its location, for the site where it is built represents in and of itself a symbolic reference which can be seen as a part of the point of view of the material aspects or composition as an artistic work, but is also part of its significance for different social groups, as a changing reference through different epochs, analized with reference to the concept of "dominion of memory" issued by Foucault.

Recepción: 5 de marzo de 2015. / Aceptación: 17 de agosto de 2015.

* El Colegio de México, A.C., ferncisneros@gmail.com 
Key words: Dome of the Rock; Semitic Sanctuary; Jewish Temple; Christian Jerusalem; Islamic Conquest of Palestine.

\section{Introducción}

El Domo de la Roca constituye el monumento del arte islámico al que se le han dedicado más estudios en los años recientes, lo que denota la importancia que reviste como obra arquitectónica y es reflejo de la influencia que puede haber ejercido a través de patrones decorativos sobre el arte musulmán.

Sin embargo, de manera paralela y por revestir a lo largo de su existencia una gran importancia, el Domo y el Haram han inspirado discursos que exaltan su naturaleza como emplazamiento sacro, y reafirman una concepción capaz de permear las mentalidades a lo largo de los siglos. Al tratarse de una obra que ha atravesado varias épocas, las interpretaciones en torno de ella necesariamente se han modificado. A este respecto, es de gran interés la propuesta de Foucault consistente en una dicotomía entre continuidad y discontinuidad dentro de un "dominio de memoria".

A lo anterior es necesario agregar que, en el caso particular del Domo, además de manifestarse una simbología poseedora de significados como obra, un "dominio de memoria” variable según cada época, está aquella de su propio emplazamiento. El lugar en el que se halla erigido representa por sí mismo un "semióforo", que, de acuerdo con la concepción definida por Krzysztof Pomian, es un objeto que puede estudiarse desde el punto de vista tanto de su aspecto material como del significante, y a la vez los significados que le son conexos se ven transmitidos por medio de textos o imágenes; un semióforo constituye per se una referencia simbólica obligada, y puede ser la base de una interpretación diversa para diferentes grupos, que le asignan un valor iconológico que va más allá de sus propias

${ }^{1} \mathrm{El}$ "dominio de memoria" es producto de la continuidad, alimentado por la tradición, y una serie de influencias, donde entran en juego semejanzas y repeticiones, lo cual incluso genera continuidades irreflexivas que se manifiestan a lo largo de un proceso. Michel Foucault, La arqueología del saber, México-Buenos Aires-Madrid, Siglo XXI, 1970, pp. 25 y ss. 
características como obra de arte,$^{2}$ algo que será muy claro en la época contemporánea respecto al Domo, en la disputa y los choques que ha producido, alimentados por tendencias radicales que lo reclaman, entre las que incluso algunas llegan a amenazar su existencia.

\section{El templo salomónico, sus antecedentes e interpretaciones predominantes}

Sin lugar a dudas, hubo asentamientos desde hace milenios en el área de Jerusalén; su nombre aparece ya bajo una forma reconocible en los archivos de Tell el-Amarna; más tarde, el texto bíblico la reporta como la capital de un pueblo denominado jebuseo. En Josué xv: 63, donde culmina la lista de las poblaciones exterminadas por los hebreos, se menciona que "a los jebuseos que habitaban en Jerusalén no pudieron exterminarlos los hijos de Judá, y así el jebuseo prosiguió habitando Jerusalén con los hijos de Judá hasta el presente". ${ }^{3}$

La cima del monte representaba un emplazamiento sacro, el cual corresponde a una roca sagrada, un betilo, la piedra fundacional, el omfalós u ombligo del mundo. ${ }^{4}$ El santuario abarcaba todo un conjunto donde, como en este caso, se encuentran asociados varios elementos: la roca, el árbol, la fuente, la cueva y aun el templo o el comedor donde se efectuaba el banquete ritual posterior al sacrificio, lo que constituía el sitio de devoción cultural de los semitas, identificable con la apelación bíblica de "lugar alto" (bamá; plural, bamot). En múltiples casos, esa acrópolis representa el núcleo en torno del cual se desarrolla una población. ${ }^{5}$

${ }^{2}$ Krzysztof Pomian, Sobre la historia, Madrid, Cátedra, 2007, pp. 110 y ss.

${ }^{3}$ El fragmento se encuentra repetido en Jueces I: 21, aunque contradice lo afirmado poco antes en Jueces I: 8: "Los hijos de Judá atacaron Jerusalén, y luego de pasar a cuchillo a sus habitantes, entregaron la ciudad a las llamas".

${ }^{4}$ Del griego báitylos, baitýlion, los que dieron en latín baetylos, baetulus, de origen semítico, la "casa del dios", bayt al-lâh.

${ }^{5}$ James George Frazer (El folklore en el antiguo testamento, México, Fondo de Cultura Económica, 1981, pp. 33 y ss.) menciona los ejemplos de Betel, Gezer y Siquem, Moreb, Mamré, 'Ofra y Gaba'a, así como la perdurabilidad de tales formas de culto entre la población local. W. Robertson Smith alude a las cuevas y el bosquecillo sagrado en Religion of the Semites with a New Introduction by Robert A. Segal, Nueva 
La tradición judaica reclama la roca como lugar del sacrificio de Isaac, y la ciudad se relaciona con Melquisedec, el "rey de Shalem", al que se cita para resaltar el valor sacerdotal de la realeza, como rey del lugar, quien bendice a Abraham, pero se encuentra ausente en las prolijas listas genealógicas. ${ }^{6}$ Así, el Génesis Rabbá afirma que era el mismo Shem. Para los cristianos, Melquisedec "no tiene padre ni madre" y encarna el eterno sacerdocio. Su sacrificio consistía en pan y vino, y anuncia el advenimiento de Jesús, como es representado en los mosaicos del ábside de San Vidal, en Ravena. ${ }^{7}$

Sin embargo, cualquier intento de descripción del significado simbólico del Domo y el conjunto del Haram resultaría inadecuado si no hace referencia a la evolución posterior sufrida por el lugar. El templo salomónico se construyó en asociación con el palacio real, del cual constituía un anexo, característica común a toda el área del Medio Oriente antiguo y que ya se conocía a mediados del siglo XIX. ${ }^{8}$ Es interesante notar que esto ha repugnado a quienes han idealizado el templo, incluidos algunos investigadores, que insisten en resaltar su carácter excepcional. ${ }^{9}$

Brunswick-Londres, Transaction Books, 2012 (facsímil de la edición de 1892), pp. 187 y ss. En ocasiones, los textos destacan el carácter del santuario que domina el poblado, como en el caso de Ramá, donde Saúl fue consagrado rey (I Samuel IX: 25 y ss.).

${ }^{6}$ Salmos 75-76 y 109-110, Génesis xIv: 18-24.

${ }^{7}$ A partir de la Epístola a los hebreos v: 6 y vII: 1; el obispo y heresiógrafo Epifanio (segunda mitad del siglo Iv) menciona que los fenicios lo reclamaban como su antepasado, lo que lleva a suponer un origen cananita: "A pesar de que las tardías leyendas de los judíos lo hacen el primer constructor de Jerusalén, 'sobre la tumba de nuestro padre Adán', pienso que puede asumirse con claridad que una corriente de la tradición judía, quizá especialmente fuerte en Palestina, donde la conociera san Epifanio, menospreciaba el pasado gentil de la Jerusalén anterior a David, e insistía específicamente en el carácter específicamente judío de la piedra fundacional que aún marcaba el Santo de los Santos" (George Every, Christian Mythology, Londres, Hamlyn, 1970, p. 53). La identificación con Shem también aparece en Angelo Rappoport, Ancient Israel Myths and Legends, Nueva York, Bonanza, 1987, vol. I, p. 260.

${ }^{8}$ Así lo menciona Ernest Renan (Euvres complètes, ed. Henriette Psichari, París, Calmann Lévy, 1947, vol. vI, cap. XII, "Le temple”, pp. 399 y ss.). Th. A. Busink menciona a su vez el caso de Qatna (Mishrife, Siria, entre 3300 y 1200 a.e.c.), donde la sala del trono y el santuario se encontraban íntimamente asociados (Der Tempel von Jerusalem von Salomo bis Herodes: Eine archäeologisch-historische Studie unter Berucksichtigung des Westsemitisches Tempelbaus, Leiden, E. J. Brill, 1979, p. 512).

${ }_{9}$ Busink critica la afirmación de Adolphe Lods: "el nuevo santuario era ante todo la capilla del palacio" (Israël des origines jusqu'au milieu du vII ${ }^{e}$ siècle, París, La Renaissance du Livre, 1932, p. 480), lo cual pudo haber sido en sus comienzos, citando 
Al respecto, la denominación misma del templo salomónico en hebreo, hekhal (árabe, haykal), proviene del acadio ekall ${ }^{u}$, y a su vez del sumerio é-gal, lenguas en que designa tanto el templo como el palacio real. Al igual que los templos del área, en Siria y Mesopotamia, ${ }^{10}$ la acrópolis jerosolimitana poseía un espacio que hacía posible el funcionamiento del templo, situado entre éste y el palacio. Sin embargo, para la evolución posterior, los estudios sobre la Biblia se preocupan mucho más por el mobiliario y demás accesorios - los cuales fueron con el tiempo empleados para pagar el tributo o sufrieron pillajesque por las modificaciones del conjunto, aunque el texto afirma que durante el reinado de Josafat se agregó un nuevo patio, donde el rey reunió a gente "de todas las poblaciones de Judá", con lo cual se sobreentiende que el patio preexistente fue reservado al sacerdocio. También se menciona una "entrada de los caballos" y una "puerta del fundamento" que comunicaban el templo con el palacio. ${ }^{11}$

Al tomar en cuenta que el conjunto constituía un "lugar alto" según el prototipo regional, la adopción de la ciudad como capital por David la había puesto en un lugar destacado entre los santuarios que protegieron los primeros reyes: Saúl, David, Salomón y Acab. Sin embargo, esa primera etapa "anfictiónica" toca su fin con las reformas de Josías (siglo viI a.e.c.): el templo que dominaba la ciudad, vecino al palacio real, debía ser considerado el único santuario legítimo del reino de Judá, aquel que los varones debían visitar en las festividades anuales. ${ }^{12} \mathrm{~A}$ ello

a autores que rechazan este uso "privado", y agrega: "Frente a la interpretación de una función del templo salomónico tan limitada se levanta de manera rotunda el significado universal de lo sagrado" (ibid., p. 618). En épocas recientes, la relación del templo con la monarquía ha sido soslayada para dar lugar a una anacrónica interpretación como "santuario nacional".

${ }^{10}$ Roland de Vaux, Les institutions de l'Ancient Testament, París, Les Éditions du Cerf, 1960, t. II, pp. 94 y ss. Otros ejemplos, que se refieren a la simple estructura, se extienden desde la costa siria actual: Tell Tu'eyma, Zinjirli, Biblos, Karkemish, además de Hatzor, santuario que poseía también un patio cuadrangular, como al parecer era el primitivo en Jerusalén.

${ }^{11}$ Mencionado en I Reyes VII: 2, XI: 19; II Reyes XI: 16-19, XV: 15-35; II Crónicas Xx: 4-9, XxIII: 15 y 20, xxvII: 3 (André-Marie Gerard [ed.], Dictionnaire de la Bible, París, Robert Laffont, 1989, “Temple”, pp. 1315-1316). La puerta al sur del templo que comunicaba con el palacio real se menciona también en Jeremías XVII: 19, Xx: 2, Xxvi: 10, y Ezequiel Ix: 2.

12 Pascua, Shabu ot y Sukkot (Deuteronomio, XvI, 16). La reforma pretendía una 
agregó una política de destrucción de otros lugares altos donde se extendiera su poder. ${ }^{13}$ Con todo, la exclusividad tardó en ser acatada, en especial entre los remanentes del reino del norte.

Posterior a la destrucción del recinto salomónico llevada a cabo por Nabucodonosor (siglo vil a.e.c.), el templo se volvió a levantar durante el reinado de Zorobabel (siglo vi a.e.c.), aunque la restauración fuese la obra de Nehemías, quien excluyó a los remanentes del reino de Israel, los que mantuvieron su propio templo en el monte Garizim, en torno del cual se desarrolló la comunidad samaritana. ${ }^{14}$ El templo de Jerusalén restaurado mantenía espacios abiertos para su funcionamiento como santuario: atrios o patios reservados para funciones específicas. ${ }^{15}$ Resulta difícil determinar si el palacio desaparece del conjunto, pero los asmoneos, los cuales no podían pretender una ascendencia davidiana, posiblemente ocuparan una residencia separada del área del templo. ${ }^{16}$ Posteriormente, el recinto

nueva modalidad de legitimación real, a partir del descubrimiento en el templo de un supuesto libro antiguo, y no sería aprobada hasta que los sacerdotes consultaron a la "profetisa" Huldá - en hebreo, el nombre de un roedor: el topo o la rata-, quien aportaría la sanción definitiva (II Reyes XXII: 11), a lo cual no se da mucho relieve, en contraste con la importancia que alcanzaría el estatus de exclusividad del santuario (Martin Noth, Histoire d'Israël. Des origines à la destruction du Temple, París, Payot, 1985, pp. 283 y ss.).

${ }^{13}$ La supresión se llevó a cabo verosímilmente en forma cruenta (I Reyes XxIII: 4-20). Algunos autores, como Finkelstein (Israel Finkelstein y Asher Silbermann, David y Salomón: en busca de los reyes sagrados de la Biblia y de las raíces de la tradición occidental, Madrid, Siglo XXI, 2006), exponen la designación del santuario único como un fenómeno autónomo, pero la reforma pudo seguir el ejemplo de Babilonia, como sugiere M. Weinfeld ("Cult Centralization in Israel in the Light of a Neo-Babylonian Analogy”, Journal of Near Eastern Studies, vol. XxIII, núm. 3, julio de 1964, pp. 202-212). W. Robertson Smith (Religion of the Semites..., op. cit., p. 200) menciona ejemplos de lugares altos celebrados por patriarcas o reyes; así Abraham (Génesis XII: 6) pasa por ser el fundador del santuario de Siquem, mientras en Isaías LXV: 3-7; LXVI: 17, aflora ya la actitud condenatoria.

${ }^{14}$ Este templo continuaba el del cercano Siquem, donde Roboam fuera consagrado rey (I Reyes XII: 1); véase Gerard (ed.), Dictionnaire de la Bible, op. cit., "Sichem", pp. 1278-1279, y “Samaritains”, pp. 1237-1238.

${ }^{15}$ En I Macabeos IX: 54-56, se menciona con animosidad el intento del sumo sacerdote helenizado Álcimo -Elyaqim-de derribar las barreras entre los distintos atrios. Lo mismo aparece en Flavio Josefo, Antigüedades judías, ed. José Vara Donado, Madrid, Akal, 1997, XII: 413, p. 713.

${ }^{16} \mathrm{La}$ idea de separar el templo del palacio se remonta al versículo condenatorio en Ezequiel XLIII: 7-8, en vituperio del reino de Israel. Los asmoneos parecen tratar de apegarse en todo a los preceptos de la ley. Con todo, durante la profanación de Antíoco Epifanes, funcionó por un breve periodo un templo alternativo en Masfa -árabe, Tell 
sacro fue ampliado por Herodes el Grande al sur, sobre el 'Ófel, y daba un amplio lugar a los gentiles. Aunque en esta última construcción el palacio no se encontraba sobre la explanada, el conjunto mantenía una relación con el monarca, pues incluía el pórtico real, el Herodión, una stoá griega a lo largo del muro sur. ${ }^{17} \mathrm{El}$ conjunto representaba las mayores dimensiones alcanzadas por el santuario judaico, la enorme explanada presente hasta hoy; pero a pesar de que la obra herodiana habría reemplazado el conjunto anterior, se agrupa con el de Zorobabel en el periodo del segundo templo, lo que realzaba la continuidad de sus funciones.

Sin embargo, dada la característica de exclusividad que poseía, la destrucción del templo herodiano en el año 70 implicaría fuertes transformaciones para el culto y la organización religiosa, ${ }^{18}$ pues su ausencia implicaba la imposibilidad de los ritos de sacrificio de bestias en la tradición judaica, y acarrearía la desaparición del sacerdocio. ${ }^{19}$ Aludir a un sitio alternativo en el que se realizaran sacrificios resultaba inconcebible, sólo para referirse de forma condenatoria respecto al santuario samaritano sobre el Garizim. De tal manera, el judaísmo evolucionará hacia nuevas formas de religiosidad, en torno de la sinagoga, $y$ el consejo de ancianos, el sanedrín.

Con todo, aun destruido, el templo se mantuvo en la mentalidad judaica, que continuaba considerando su emplazamiento como el axis mundi, el punto "más alto", el "ombligo de la tie-

el-Nasbe-, un antiguo "lugar alto" (I Macabeos III: 46-49. Noth, Histoire d'Israël, op. cit., p. 377), sin que se mencione la celebración de sacrificios. Mientras tanto, bajo la anuencia de los lágidas, se fundaba el templo de Elefantina (Flavio Josefo, Antigüedades judías, op. cit., XIII: 62-73, p. 730).

${ }^{17}$ Flavio Josefo concede gran interés a la relación del conjunto del templo con el monarca: "En el sector occidental del recinto amurallado se levantaron cuatro puertas, una se dirigía al palacio real a través del barranco", en el lado sur (ibid., XV: 410, p. 946).

${ }^{18}$ Es posible preguntarse si tal destrucción era evitable dentro del esquema de la política de la dinastía que gobernaba en Roma. Vespasiano había clausurado el templo judaico alternativo de Leontópolis (Egipto), que tampoco gozaba del reconocimiento del sacerdocio oficial (James Rives, "Flavian Religious Policy and the Destruction of the Jewish Temple", en J. Edmonson et al. [eds.], Flavius Josephus and Flavian Rome, Oxford-Nueva York, Oxford University Press, 2005, p. 153).

${ }_{19}$ Flavio Josefo cuenta ochenta y tres "sumos sacerdotes" desde la época de David y Salomón hasta la destrucción del año 70, todos pertenecientes a la estirpe de Sadoq (Gerard [ed.], Dictionnaire de la Bible, op. cit., "grand prêtre”, pp. 453-456). 
rra”, ahora ligado al mesianismo en la espera de su restauración, y la fecha de Tish á be-ab, la efeméride anual que conmemora su pérdida - tanto la efectuada bajo Nabucodonosor como la segunda por Tito-, es un día de duelo.

Jerusalén mantendría en el judaísmo su estatus simbólico, a pesar de la decadencia y el abandono posterior al año 70, en que sufriera de manera atroz la campaña de Tito, junto con la región de Judea, tierra adentro; mientras que, sobre la costa, Cesarea, con una presencia importante de cristianos, permaneció en cambio casi indemne como la ciudad más importante de la zona. El abandono acabaría en 130, tras el ascenso de Adriano al trono imperial: el emperador decidió construir una nueva ciudad sobre el antiguo emplazamiento jerosolimitano, la Aelia Capitolina, pero la obra se interrumpiría del todo hasta que fuera capaz de reprimir, en 135, la revuelta de Barcoquebas - Bar Kokhbá-, durante la cual se eleva Eleazar el Moda í al grado de sacerdote. ${ }^{20}$ Dicha restauración del rango sacerdotal implicaría que durante el breve periodo en que los alzados ocuparon Jerusalén se restauraran los sacrificios en el templo o el área de la explanada.

La Aelia Capitolina de Adriano, construida acorde con el plano de una colonia romana, implicaba además una urbanización diferente a cualquier patrón anterior que haya seguido la ciudad. Estaba dotada de dos vías principales, cardo y decumano, en intersección perpendicular al lado de la colina del Gólgota, sobre cuya cima, externa a la capital herodiana, a más de trescientos metros al oeste del antiguo templo, se erigió un templo dedicado a Afrodita - deidad asociada con el local Adonis-, más tarde reemplazado por el Santo Sepulcro de

${ }^{20}$ Se había dado en la diáspora bajo Trajano una revuelta de Cilicia a Egipto en 117, la que culmina en Judea con el movimiento de Bar Kokhbá - nombre de guerra, en alusión a Números xxIv: 17, como profecía de contenido monárquico-. Barcoquebas obtuvo el reconocimiento de mesías salvador por el rabbi 'Aqîba; empero, la revuelta fue posteriormente desconocida por la literatura rabínica, de no ser para llamar al líder Bar Kozbá "hijo de la mentira”. La actual historiografía israelí lo celebra como héroe nacional, mientras que la tradición judaica se enfocó hacia el rabino - figura comparable a los padres de la Iglesia, también capaz de mostrar una gran intolerancia-, e igualmente equipararía a Adriano con Antíoco Epifanes, como déspota opresor, mientras que el apologeta cristiano Orosio (siglo v) lo consideraba un instrumento "vengador" de Dios (Félix M. Abel, Histoire de la Palestine depuis la conquête d'Alexandre jusqu'à l'invasion arabe, París, Lecoffre, 1952, vol. II, p. 91). 
los cristianos. La ciudad, representada a la manera helenística como una deidad femenina dotada de corona mural, ${ }^{21}$ destinaba en su traza el espacio de la explanada -denominada en latín la quadra; kódra, en griego- al gran santuario del Júpiter Capitolino, el cual habría de dominar el espacio superior, como otrora el templo herodiano. ${ }^{22}$

Tal situación se modificaría con el advenimiento del cristianismo: Helena, madre del emperador, arriba en 330 a Jerusalén, donde anuncia el hallazgo de la cruz del Salvador, inventio crucis. Casi inmediatamente se inicia la construcción del complejo del Santo Sepulcro, la basílica de la Natividad en Belén, y la Eleona en el Monte de los Olivos, al tiempo que comienza la destrucción o el abandono e incuria de los santuarios paganos en la zona: la voluntad imperial emprende así la construcción de la “Tierra Santa”. Entre los lugares sagrados del cristianismo - loca sancta-, el principal, el Santo Sepulcro, estaba concebido en su plan para constituirse en centro de peregrinaje, $y$ funcionaba como tal aun antes de terminado, cuando lo visitara el peregrino de Burdeos, en 333. Dos años más tarde, el propio Constantino celebra el trigésimo aniversario de su ascenso al trono con una peregrinación a Jerusalén, momento en el que parecen estar acabadas las obras de los tres "antros" del cristianismo, denominados así al estar asociados con un hipogeo.

En contraste, al derruir el templo capitolino se condensaba la idea del cristianismo consistente en que debía reinar la devastación sobre la quadra y mostrar la ostensible ruina del templo como el emblema de la desgracia del culto de la llamada "antigua alianza", al darle un sentido escatológico - a partir de su interpretación de los Evangelios-y otorgarle validez como evento histórico, a la vez que contribuía a ello abiertamente. $^{23}$

${ }^{21}$ Thomas Ganschow, “Aelia Capitolina”, en Lexicon Iconographicum Mythologiae Classicae, Supplementum, Zúrich-Düsseldorf, Artemis, 1997, p. 505.

${ }^{22}$ Friedrich Buhl, "al-Kuds", en M. Th. Houtsma et al., First Encyclopaedia of Islam, Leiden-Nueva York, E. J. Brill, 1993, vol. Iv, p. 1094.

${ }^{23}$ La relación simbólica entre Jesús y el templo es estudiada por Giancarlo Biguzzi, "Yo destruiré este templo": El templo y el judaísmo en el Evangelio de Marcos, Córdoba-Madrid, Ediciones El Almendro, 1992. Sin embargo, en los primeros siglos del cristianismo se la interpretaba plena de repercusiones materiales, y el poder en Constantinopla consideraba importante que la desolación reinase sobre el sitio. 
Lo anterior en gran medida coincidía con la conducta de los cristianos ante los antiguos lugares sagrados, la cual se manifestó a través de dos actitudes opuestas: por una parte, se menciona su ostensible "repugnancia" respecto a los sitios consagrados a los dioses paganos, lo que planteaba separar los lugares del culto entre ambas religiones: con el triunfo de la nueva fe se manifiesta una clara voluntad de obstaculizar su funcionamiento e incitar su profanación. ${ }^{24}$ En contraste, se desarrolló la estrategia de sobreponer la devoción cristiana sobre los sitios de culto de los dioses anteriores, resacralizándolos, tal como la evangelización lo pondrá en marcha siglos después en el Nuevo Mundo; así tenemos el ejemplo de la basílica de la Natividad en Belén, construida sobre el bosquecillo sacro de Adonis. En especial, se manifiesta el interés por anular los "cultos lascivos" característicos de los ritos de la fertilidad, como las "adonías", superponiendo el culto y la devoción a los santos cristianos.

Si algo no variaba al cristianizarse el Imperio, era que en la búsqueda por asimilar la ciudad y reconstruirla como centro de la fe se mantenía la interdicción de su acceso a los judíos. Así, el cronista apologético Orosio (m. ca. 418) interpretaba la destrucción del templo y Jerusalén como la venganza divina por la sangre derramada de Cristo y, en consecuencia, los judíos nunca debían volver a establecerse ahí: toda relajación en cuanto a la veda del santuario para los fieles de la "antigua alianza" enfrentaba la aversión de los cristianos devotos. La excepción la constituía el Tish á be-ab, en que se les permitía acercarse para llorar su ruina: hacia 333, el Peregrino de Burdeos relata que "una vez al año, los judíos eran admitidos para ungir la roca, lamentar su suerte rasgando sus vestimentas, e irse", prácticas también testadas por el cronista san Gregorio Nacianceno (m. ca. 390) y san Euquerio (siglo v). ${ }^{25}$ En ese caso, la interdic-

${ }^{24}$ Cristoph Markschies, Estructuras del cristianismo antiguo. Un viaje entre mundos, Madrid, Siglo XXI, 2001, p. 53, a lo que agrega que excavaciones en varios lugares, como Afrodisias (Asia Menor), han descubierto que las prácticas de destrucción estaban muy extendidas. Un ejemplo radical lo constituye el incendio y profanación del Marnéion de Gaza, que urdió el obispo Porfirio.

${ }^{25}$ De acuerdo con K. A. C. Creswell (Early Muslim Architecture, Nueva York, Hacker, 1979 [edición corregida, 1969], t. I, vol. 1, pp. 30 y ss.), la roca sobresaliente del terraplén en épocas del templo herodiano habría funcionado como altar donde se ofrendaba incienso, lo que pudiera sustentarse tanto en Flavio Josefo como en la 
ción para los judíos de ingresar en la quadra promovería el desarrollo de una forma de devoción, sin que sean claros los pormenores que más tarde la desviarían hacia el Muro de los Lamentos, próximo al ábside de Herodes. ${ }^{26}$

En ese contexto, si para los judíos el mayor anhelo era la restauración del templo, para el mesianismo cristiano su ruina era necesaria. Aun la misma denominación, "templo", se asociaba con usos reprensibles: el lugar del culto cristiano era la "asamblea", la iglesia - ekklèsía-, en lugar del "templo", que designaba el de los dioses paganos, o bien el judaico. Las motivaciones se encontraban definidas a priori dentro de una valoración de los espacios, la cual giraba en torno del concepto de sacralidad, y en contraparte la profanación o demolición de un sitio sagrado poseía tremendas implicaciones ideológicas que exigían acciones particulares. Así, en el caso del Santo Sepulcro, con la anuencia del patriarca Macario, responsable del plan constantiniano, no solamente se removieron los muros y los cimientos del templo de Venus, sino que se extrajo tierra - pues se consideraba enturbiada por los sacrificios- para hacer aflorar al nivel superficial el hipogeo, cuyo edículo funerario marcaría el eje del complejo basilical, una vez aplanada la cima del promontorio del Gólgota, previo a la construcción del nuevo monumento. ${ }^{27}$

De esta manera, la romanización de la ciudad y la elevación de los santos lugares como meta del peregrinaje cristiano

Mishná, y posiblemente pueda identificarse como el altar mencionado en I Reyes vIII: 62 y ss.

${ }^{26} \mathrm{El}$ "nueve del mes de ab" conmemora tanto la destrucción por Tito del segundo templo como la del salomónico por Nabucodonosor, ambas acaecidas en fechas cercanas. El centro de la plegaria judía era el emplazamiento devastado del templo. Las leyendas y prácticas relacionadas con el carácter sacro del muro occidental -Kotel hama rabí- comienzan a hacer su aparición (véase "Muro de las Lamentaciones", en Eduardo Weinfeld et al. [eds.], Enciclopedia Judaica Castellana, México, Editorial Enciclopedia Judaica Castellana, 1950, t. vIII, p. 34).

${ }^{27}$ Béatrice Caseau, "Sacred Landscapes", en G. W. Bowersock, P. Brower y O. Grabar (eds.), Late Antiquity. A Guide to the Postclassical World, Cambridge-Londres, Harvard University Press, 1999, p. 31. Según los apologistas cristianos, en particular Eusebio, el promontorio no era natural, sino que los paganos habían amontonado tierra con el reprobable propósito de ocultar la tumba de Cristo y obstaculizar la devoción cristiana, algo que por siglos se aceptó como un hecho, aunque al parecer su objetivo era sólo elevar el terraplén del templo de Afrodita. La plausible evolución del sitio se ilustra en Meir Ben-Dov (Historical Atlas of Jerusalem, Jerusalén, Continuum, 2002, p. 149). 
vienen a ser un factor en la continuidad de la vida urbana, que caracteriza su decadencia. Tal situación no cambiaría con el intento emprendido por Juliano, apodado el Apóstata, por renovar el culto en el templo judaico en 363, año en que restaura el culto de Apolo en Antioquía, para escándalo de los cristianos, que lo acusan de actuar impulsado por el reprobable afán de contrariar las profecías. ${ }^{28}$ Aunque en la intención de reconstruir el templo, al equiparar el tratamiento del culto judaico con el pagano, sus motivaciones no parecen tan obvias, posiblemente considerara que los judíos poseían un dios particular, y desconociera su relación con el cristianismo. ${ }^{29}$

Sin embargo, el intento de reconstrucción del templo no avanzó, pues al inicio de los trabajos —que quizás solamente comenzaban a escombrar el sitio de los vestigios del capitolio de Adriano- brotaron llamaradas que sembraron el terror entre los albañiles, y san Gregorio Nacianceno sentenciaría que todos los trabajos emprendidos con tan impío objetivo se verían siempre frustrados por intervención de la voluntad divina, manifestada mediante el milagro, aunque la explicación actual del fenómeno alude a una acumulación de gases en el subsuelo.

Ante la instauración del cristianismo como religión única sobrevienen las revueltas paganas, que estallan al ponerse en práctica la prohibición de los sacrificios; asolan la Beqấ y las cuencas del Litaní y el Orontes, y afectan también Galilea y la cuenca del Jordán. Otra revuelta más, la samaritana, representa la última rebelión en la zona. En ambos casos, los rebeldes

${ }^{28}$ La violencia con que se impuso el cristianismo como religión única había provocado reacciones en su contra, e incluso generó un pacifismo mesiánico que se presentaba como alternativo a su milenarismo. A. Momigliano (en Ensayos de historiografía antigua y moderna, México, Fondo de Cultura Económica, 1993, p. 130) cita a este respecto la Sortes Virgiliana y el Relato de vida de Probo. Fernand Mourret (Histoire générale de l'église, t. II : Les pères de l'église, París, Bloud \& Gay, 1928, p. 175 y ss.) cuenta que los paganos reaccionaron en varios casos tomando venganza, lo cual interpreta como una "última persecución" contra el cristianismo.

${ }^{29} \mathrm{Al}$ parecer, Juliano encontraba en el judaísmo paralelos cultuales con la religión helenística (Günter Stemberger, El judaísmo clásico. Cultura e historia del período rabínico, Madrid, Trotta, 2011, pp. 32-33). En Antioquía, la restauración del templo de Apolo implicaba la destrucción de un martyrium cristiano, e incluía la remoción de los restos del santo, pues para los paganos la presencia de cadáveres profanaba la tierra (Juana Torres, "La ocupación de espacios sagrados como fuente de conflicto entre paganos y cristianos", 'Ilu. Revista de Ciencias de las Religiones, Anejo XVIII, 2007, pp. 88-89, n. 16). 
destruyen numerosas iglesias, pero al concluir la represión, el poder cristiano ordena edificar basílicas votivas, las cuales aparecen en el mosaico de Ma'dabâ —en árabe coloquial, Madeba-, donde están representados los diversos monumentos de la Aelia Capitolina en su máximo esplendor como ciudad santa del cristianismo. ${ }^{30}$

Restaba aún uno de los periodos más relevantes de la Jerusalén bizantina, que se inició precisamente con un peregrinaje, el realizado por la emperatriz Eudocia en 438 . La consorte de Teodosio II arriba a la ciudad con el propósito de visitar los santos lugares, bajo la guía de san Cirilo de Alejandría. Empero, vuelve entre 441 y 442 para establecerse definitivamente, en lo que se considera un exilio de la corte de Constantinopla, adonde nunca regresó, por lo que pasó a ser la auténtica gobernante de la provincia hasta su muerte, en 460, diez años después de quedar viuda. ${ }^{31} \mathrm{La}$ emperatriz exiliada hace todo por detener el deterioro urbano: ordena construir y restaurar, y se le atribuyen varias obras, civiles y religiosas; la basílica de San Esteban, el protomártir del cristianismo, la más importante de ellas, e incluso se la relaciona con la llamada Tumba de la Virgen -octágono que abarcaba un ábside en su lado oriental-, atribuida también al emperador Mauricio (r. 582-602), su reconstructor o restaurador; monumento que, sobre el valle de Josafat y próximo a la Puerta Áurea, daría origen a la denominación del mismo valle en árabe: Wâdî Maryam, el "valle de María".

Sin embargo, la acción de Eudocia va aún más lejos: se implica en las controversias teológicas apoyando el monofisismo y enfrentado al cristianismo niceno oficial, lo que no es sorpren-

${ }^{30}$ El detallado estudio de Victor Roland Gold ("The Mosaic Map of Madeba", Biblical Archaeologist, vol. xxI, núm. 3, 1958, pp. 49-71) demuestra la factura posterior a Justiniano; incluye la ubicación detallada de los monumentos en el mapa musivo.

${ }^{31}$ El exilio de Eudocia tiene características tan excepcionales como su personalidad: Athenaís o Atenaida, de su nombre original, había recibido el bautizo como Eudokía con el propósito de desposar al emperador, pero se torna profundamente cristiana bajo el influjo de san Cirilo, traduce el Pentateuco a "la lengua de Homero" y escribe martirologios en una poesía de estilo arcaizante, de los que se conserva en gran parte el de san Cipriano, el cual alimenta la relación del santo con la magia. Permanece en el gobierno de Jerusalén a pesar de influir en las disputas teológicas sosteniendo una posición divergente a la de Pulqueria, su cuñada además de esposa de Flavio Marciano, sucesor de Teodosio, la que sería reconocida como santa por la iglesia, y pudo haber tenido responsabilidad en su exilio. 
dente si se toma en cuenta que era la corriente predominante en Siria. Además, algunos historiadores afirman que permitió el retorno de los judíos a la ciudad santa, lo cual parece en verdad difícil, pues contrasta con las medidas de los soberanos cristianos de la época, y además también sería contrario al parecer de su mentor, san Cirilo. ${ }^{32} \mathrm{Al}$ mismo tiempo, despliega una gran actividad de la que nace un nuevo patriarcado cristiano en Jerusalén, al sostener la posición jerárquica para su reconocimiento por las sedes ya existentes de Antioquía y Alejandría, que contemplan con recelo el hecho. Cierto hecho probablemente lo facilitaría: el título de nasí o rabbán, al que los cristianos denominaban patriarca judío, terminó cuando Teodosio II dejó de refrendar un sucesor para Gamaliel VI; de manera que al final de su reinado surge en su lugar un nuevo patriarcado cristiano, con la mediación de su esposa. ${ }^{33}$

Para la Jerusalén instaurada como sede patriarcal, el mayor vuelco sobrevendrá del exterior, a causa del enfrentamiento contra el Imperio persa: en 614, el rey Cosroes captura la ciudad. Los cronistas cristianos denuncian que, durante la ocupación, los invasores perpetran la destrucción sistemática de las iglesias de la región entera, bajo la instigación de los judíos, con la excepción de la basílica de la Natividad en Belén, donde la representación de la epifanía, con los magos en vestimentas persas, los habría disuadido de vandalizarla. ${ }^{34}$ Sin embargo, el mayor golpe sufrido por la cristiandad consistió en que Cosroes no sólo se llevó prisionero al patriarca Zacarías, sino, sobre to-

${ }^{32}$ Michael Avi-Yonah (“Jerusalem. History”, en C. Bezalel Roth [ed.], Encyclopoedia Judaica, Jerusalén, Keter, 1972, vol. IX, p. 1407) sostiene que la emperatriz autorizó tal retorno, aunque en realidad posiblemente no fuera más allá de permitir a los judíos acudir a la ciudad en otras festividades además de Tish á be-ab, pero la celebración de la Sukkot generó graves enfrentamientos con los cristianos (Karen Armstrong, Historia de Jerusalén. Una ciudad y tres religiones, Barcelona, Paidós, 2005, pp. 271-272).

${ }^{33}$ El rabbán representaba una autoridad e interlocutor reconocido por el imperio, como representante de la comunidad judía, y presidía el sanedrín. Stemberger (El judaísmo clásico, op. cit., pp. 57 y ss.) menciona a trece hasta la muerte de Gamaliel VI, anterior a 469, que se sucedían directamente en el cargo de padre a hijo, y cuyo linaje se remontaba hasta Hillel I, contemporáneo de san Pablo.

${ }^{34} \mathrm{El}$ número de los magos variaba en esa época (Louis Réau, Iconografía del arte cristiano, Barcelona, Ediciones del Serbal, 1996, t. 1, vol. 2, p. 249). Su representación en atuendos persas en el ábside de la iglesia de San Apolinar de Ravena perdura hasta nuestros días. 
do, tomó la cruz del Gólgota como trofeo a Ctesifonte, su capital, en los bordes del Tigris. Jorge Pisides, diácono de Santa Sofía, contemporáneo de los hechos, describe la captura de la Santa Cruz en términos apocalípticos, y el cronista Antíoco Estrategio los relata entablando equivalencias con los sufrimientos de la Pasión..$^{35}$

La reacción del poder cristiano es inmediata, y en 622 el emperador Heraclio conduce una expedición de rescate, tras la cual restituye la Santa Cruz en la procesión del Domingo de Ramos, pompa pensada en sus mínimas repercusiones simbólicas. ${ }^{36}$ El hecho sería celebrado en toda la cristiandad y originó una festividad mantenida por los cristianos de Medio Oriente, aunque hoy sea casi ignorada por los de otras latitudes. El cronista bizantino Teófanes (m. ca. 817) describe en su Cronografía al emperador como héroe mítico, el nuevo Alejandro Magno. ${ }^{37}$ En cambio, entre los judíos, que asumían a Roma y Constantinopla como el "imperio del mal" y esperaban la liberación por parte de Persia, el autor anónimo del

${ }^{35} \mathrm{La}$ fuente principal es la obra del monje Estrategio, escrita originalmente en griego, de la cual han sobrevivido traducciones en georgiano, armenio y árabe; afirma la “destrucción de las iglesias de la ciudad por los saqueadores judíos". José Martínez Delgado, "Las versiones árabes de La Destrucción de Jerusalén por los persas (614, d.C.)", 'Ilu. Revista de Ciencias de las Religiones, vol. XI, 2006, p. 193, n. 35.

${ }^{36}$ En Occidente, sus ecos se manifiestan en Rabano Mauro (m. 856). La fecha de la procesión fue el 21 de marzo de 629, y la puerta por la que penetrara Heraclio en la ciudad sería tapiada para que solamente el Cristo a su segunda venida la volviese a utilizar. K. Armstrong (Historia de Jerusalén, op. cit., p. 282) menciona además la posibilidad de que la Puerta Áurea se haya construido para ese efecto, pero esto implicaría que al ingresar el emperador pisara la quadra, pues dicha puerta se sitúa al frente del antiguo emplazamiento del segundo templo, y normalmente se la considera herodiana. La fecha en que se celebra la "exaltación" posiblemente sea aquella en que la cruz fue recuperada, el 14 de septiembre de 628; el papa Sergio, de origen sirio, introdujo la fiesta en Roma desde finales del siglo VII (Réau, Iconografía del arte cristiano, op. cit., t. 1, vol. 2, p. 527).

${ }^{37}$ Barbara Baert ("Héraclius, l'exaltation de la Croix et le Mont-Saint-Michel au XI siècle. Une lecture attentive du ms. 641 de la Pierpoint Morgan Library à New York", Cahiers de Civilization Médiévale, vol. LI, núm. 201, 2008, p. 5) menciona que ya en vida de Heraclio era objeto de leyendas que sobrepasaron el ámbito cristiano, entre musulmanes y judíos. L. Réau hace mención de algunas representaciones occidentales de su entrada a Jerusalén, consagrada en la Leyenda dorada (s. XIII). Heraclio, aunque no fuera canonizado, "pertenece al repertorio del arte cristiano" (Réau, Iconografía del arte cristiano, op. cit., t. 2, vol. 4, p. 71). La exaltación está incluida en el programa de la leyenda de la Vera Cruz, en la basílica de San Francisco en Arezzo, por Piero della Francesca (mediados del siglo Xv). 
Sueño de Zorobabel ligaba las expediciones persas a la redención mesiánica del yugo del "traidor" Heraclio. ${ }^{38}$

\section{La construcción del Domo a la llegada del islam}

A la conquista del islam, la quadra era un lugar definible como "semióforo", según el concepto de Pomian, un lugar simbólico lleno de atribuciones asociado a creencias antagónicas, el cual enfrenta a judíos y cristianos, donde la visión escatológica de la ruina del templo se refuerza entre estos últimos a través de leyendas que se complacen en narrar la vanidad de los intentos por reconstruirlo, especialmente el fallido proyecto de Juliano ${ }^{39}$ En contraste, en las consejas de los judíos, de fuerte tinte mesiánico, se reafirmaba la idea de su mirífica reconstrucción: sería obra divina y no humana; un tema recurrente desde Ezequiel. ${ }^{40}$

La toma de Jerusalén por los musulmanes, a consecuencia de la victoria sobre Bizancio en la batalla del Yarmûk, muestra características especiales en cuanto al tratamiento que

${ }^{38} \mathrm{El}$ enfrentamiento generaba expectativas apocalípticas. Así, Emmanuel Levinas (Más allá del versículo: lecturas y discursos talmúdicos, Buenos Aires, Lilmod, 2006, pp. 92 y ss.) cita del tratado Yomá: "Rav Iehuda dijo [...] el descendiente de David no vendrá antes de que el estado canalla de los Romanos se extienda, durante nueve meses, sobre el mundo entero"; a lo que se agregan expectativas contradictorias: "Rav Ioshua ben Levi dice en nombre del Rabí 'Roma acabará por caer en manos de Persia, pues está escrito" (Jeremías XI: 20); mas en contraste: "Persia acabará por caer en manos de Roma. Rav Kahana y Rav Asi dijeron a Rav: ¿Es posible que los constructores caigan en poder de los destructores?". La mención de Heraclio como traidor puede referirse a un cambio de actitud, en un comienzo favorable respecto a los judíos, despiadado más tarde. G. Stemberger, El judaísmo clásico, op. cit., p. 38.

39 "Desde hace seiscientos años vuestro templo está destruido [...] Dios está irritado contra vosotros [...] os ha dispersado sobre la tierra": extracto de los Trophées de Damas, en la Patrologia Orientalis XV, edición en francés de G. Bardy, París, 1903, apud Patricia Crone, "Islam, Judeo-Christianity and Byzantine Iconoclasm", Jerusalem Studies in Arabic and Islam, vol. 2, 1980, p. 68, n. 38. La misma autora resalta que en los escritos polémicos contra los judíos se empleaba como el año inicial el de la destrucción del templo, señal inequívoca de su caída de la gracia divina.

${ }^{40}$ Los temas milagrosos dominantes se relacionan con la división de las aguas: el autoproclamado mesías Theudas habría pretendido separar las del Jordán, sin éxito, y Moisés de Creta (siglo III) conminaría a sus seguidores a lanzarse a las olas desde un acantilado, por lo que perecieron ahogados varios de ellos. Haim Hillel Ben-Sasson, "Messianic Movements", en C. Bezalel Roth (ed.), Encyclopredia Judaica, op. cit., vol. XI, p. 1420 . 
recibió la ciudad, si se compara, por ejemplo, con la de Cesarea, que luego de la importancia que tuvo durante siglos desaparece de la historia de la región.

El califa Omar - 'Umar ibn al-Khattâb- entra en Jerusalén a comienzos de 638, a pocos años de la muerte del Profeta. De acuerdo con la tradición, el patriarca Sofronio había accedido a entregar la ciudad con la condición de que fuera el mismo califa, como la máxima figura de los conquistadores, quien la recibiera personalmente de sus manos. Si se toma en cuenta que en ese momento los ejércitos musulmanes podían forzar su entrada, el hecho de que el patriarca externara tal formalismo, $y$ el califa lo aceptase, denota per se el estatus particular de la ciudad. Con todo, después de avalado el acuerdo, durante la entrega se producen varios incidentes y fricciones que reflejan una tensión entre ambos dignatarios: Sofronio, a la aparición del conquistador, murmuraría: "ésta es la abominación de la desolación”-bdélygma tês erèmóseôs-, pues resintió como una afrenta el aspecto de "los bárbaros", cuyas túnicas andrajosas "ni siquiera les llegaban a cubrir las rodillas". San Teófanes refiere que el califa se había presentado con los vestidos sucios y rotos, animado por una "hipocresía satánica”; en todo caso, resalta la atribución de un acto o una apariencia al contrastar su entrada con la de Heraclio. ${ }^{41}$ En cambio, Omar y sus allegados consideraban su aspecto como muestra de la sencillez exigida por el islam, e incluso castigaron a los árabes que se habían engalanado para la ocasión.

Cuando el patriarca invita al califa a entrar con él a rezar al interior del Santo Sepulcro, éste se rehúsa: el haber acudido Omar a la ciudad podía considerarse un peregrinaje dentro de la usanza cristiana, y al parecer era así como el patriarca la

${ }^{41} \mathrm{El}$ antecedente de la locución, en hebreo pesh'a shomem y shiqqutz shomem; bdélygma tès erèmôseôs en griego aparece en Daniel VIII: 13, XI: 31, XII: 11, Mateo XIV: 15, y Marcos XIII: 14, con connotaciones milenaristas. El patriarca habría exclamado "abominación de la desolación" en referencia al conquistador, ante el aspecto del califa Omar: sus ropas de pelo de camello le incomodaron y las interpretó como signo de falsa humildad, o de barbarie (Moshe Gil, A History of Palestine, 634-1099, Cambridge-Nueva York, Cambridge University Press, 1992, p. 53). El patriarca ya la había pronunciado aludiendo en el sermón de Epifanía a los conquistadores provenientes del desierto (Abel, Histoire de la Palestine..., op. cit., p. 399). A partir de estos eventos, en varias crónicas la "abominación de la desolación" pasó a designar la fe que ellos portaban. 
concebía. La invitación al mayor lugar de culto era una actitud normal del patriarca u obispo al recibir a un conquistador, para tratar de ostentar el boato de los oficios religiosos, lo que, se esperaba, desembocaría en su conversión. Empero, la justificación que Omar aduce consiste en que si sus hombres lo ven rezar en cualquier recinto, el acto será interpretado por ellos como una toma de posesión del lugar para el islam, en tanto que él pretende dejar el sepulcro en propiedad de los cristianos, y sólo acepta orar en la capilla menor de Constantino, entonces colindante, la cual pasaría en lo sucesivo a funcionar como mezquita. ${ }^{42} \mathrm{Su}$ actitud contrasta con la adoptada en la basílica de la Natividad, en Belén, donde acepta pasar al interior y rezar en el ábside sur, en dirección de la qibla, hacia La Meca, algo que le haría dar la espalda al respiradero del hipogeo venerado como lugar del nacimiento del redentor. ${ }^{43}$ Con todo, de acuerdo con la interpretación de Teófanes, la insistencia del califa por realizar su plegaria en el mibrâb Dâwûd sería semejante: pedir que se le mostrara el sitio del templo de Salomón para "realizar sus blasfemias", las que para tal autor representaban la "abominación de la desolación". ${ }^{44}$

Sobre todo, resalta que el califa haya decidido dar especial importancia al acto de orar sobre el emplazamiento repudiado, y revocar el anatema infligido por el poder cristiano. El acto señalaría una nueva ruptura y constituye el hito que determina el fin de la época de la quadra, para dar comienzo a la del Haram:

${ }^{42}$ La mezquita anexa al Santo Sepulcro, desarrollada a partir de la capilla o del nártex, funcionó hasta las Cruzadas. De acuerdo con algunos autores, los musulmanes habrían ocupado el cuerpo de acceso de la basílica, y sería a partir de ese momento en que se practicaría al sur una entrada lateral para los cristianos, tal como se mantiene hasta hoy. Martin Biddle (ed.), The Church of the Holy Sepulchre, Nueva York, Rizzoli, 2000, p. 40.

${ }^{43}$ A pesar de lo que parece una actitud respetuosa de Omar, el cronista cristiano Eutiquio -en árabe, Sa îd ibn al-Bitrîq, patriarca melquita de Alejandría, m. 940- se quejaba con amargura de que los musulmanes "han entrado y escrito en ambos lugares [el Santo Sepulcro y la Natividad] lo que han querido".

${ }^{44} \mathrm{El}$ término mibrâb en la actualidad designa comúnmente el nicho que marca la qibla, o dirección de la plegaria, pero originalmente poseía diversas acepciones que van de "nicho" o "galería" a "estancia", "palacio", o bien una sala importante de éste, el aula regia; además de "santuario", de acuerdo con N. Rhodokanakis y B. Serjeant (G. Féhérvary, "Mihrâb”, en H. A. R. Gibb et al., Encyclopaedia of Islam / Encyclopédie de l'islam, Leiden, E. J. Brill, 1960-2002, vol. vII, p. 7). El mihrâb de David se menciona en el Corán XXXVIII: 21, donde puede comprenderse como un espacio cubierto; las distintas traducciones del versículo a lenguas occidentales oscilan entre "templo" y "palacio". 
Sofronio condujo a Omar hacia un acceso que era utilizado para descarga de escombros, al sur del recinto -cercano al ángulo del Muro de las Lamentaciones-, que en lo sucesivo funcionaría bajo el nombre de Bâb Muhammad, el cual se presume hoy identificado arqueológicamente. Ahí, el patriarca pronunciaría nuevamente: "Esto es la abominación de la desolación", refiriéndose a la quadra, y mostrando una escalera estrecha por la que no iba a acompañar al califa. Para Omar, en cambio, se trataba del sitio portentoso en que Salomón había forzado a trabajar a los genios. ${ }^{45}$

El relato de Tabarî (m. 925), uno de los historiadores musulmanes mejor considerado por autores occidentales, menciona ciertos detalles de gran interés en la descripción del evento: al acceder a la explanada, el califa pronunció la talbiya: Labbayka l-Lâbumâ Labbayka, lo cual revela que asumía ingresar a un lugar sagrado -comparable a la fórmula utilizada durante el hajj, entre Jabal Arafât y Mînâ en las proximidades de La Meca-.46 Luego, en busca del mibrâb Dâwûd, recurre a Ka'b al-Ahbâr, judío yemení convertido al islam, quien le señala la roca, ante la cual se despoja de su calzado para realizar la oración. Pero Omar se rehúsa a hacerlo; aduce que no era la roca sino la Ka ${ }^{\circ} \mathrm{ba}$, la qibla del islam. Ka'b al-Ahbâr sugiere al califa colocarse al norte de aquélla para realizar su plegaria, dirigiéndose a las dos qiblatayn a la vez, ${ }^{47}$ con lo cual uniría nuevamente a Jerusalén en dirección a La Meca. Sin embargo, al abstenerse de hacerlo, Omar muestra la voluntad de contrarrestar la identificación de

${ }^{45}$ Corán xxxiv: 13. [Los genios] "fabricaban para él cuanto deseaba, de tales construcciones" - mahârîb, plural de mibrâb- (Corán xxxiv: 12-13). El fragmento alude a la construcción del templo, y las vasijas que menciona son los calderos y la mar de bronce. Con todo, la idea de Salomón sometiendo los vientos y los demonios a su servicio, por la gracia de Dios, es común al Corán - XXXVIII, 36- y a la literatura rabínica, donde también los emplea para construir y fabricar objetos (Aaron Rothkoff, "Solomon. In the Aggadah", en C. Bezalel Roth [ed.], Encyclopoedia Judaica, op. cit., vol. Xv, p. 107). Incluso se insiste en que hay categorías de demonios constructores, así

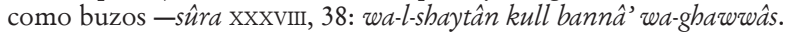

${ }^{46}$ La talbiya: "Heme aquí, Señor, he acudido [a tu servicio]" constituye un uso que precede al islam; representa un signo de entrada al estado de ihrâm o consagración al acceder a un área sagrada. Se daban diversas fórmulas de talbiya, empleadas en diferentes santuarios. Toufic Fahd, "Talbiya”, en Gibb et al., Encyclopaedia of Islam / Encyclopédie de l'islam, op. cit., vol. x, p. 160.

${ }^{47}$ Oleg Grabar, The Shape of the Holy. Early Islamic Jerusalem, Princeton, Princeton University Press, 1996, p. 47. 
lo musulmán con lo judaico, que con tal acto habría efectuado. El lugar preciso que al fin escogiera seguirá siendo punto de debate, aunque al dirigirse hacia La Meca, le habría dado más bien la espalda: sobre el lado oriental del transepto de al-Aqsà, un espacio ostenta el nombre de Jâmi' 'Umar, mezquita de Omar, lo que podría ser una indicación fidedigna del lugar escogido, ${ }^{48}$ con lo cual los vestigios entre los que rezó el califa, y había saludado con la fórmula del takbîr: Al-Lâbu akbar, habrían sido en realidad los del Herodión.

Una vez realizado el acto, como había caído la noche, esperaría en vela la plegaria del alba recitando tanto la sûra de los banî Isrầ' $̂ l$ como la sûrat sâd -la XVII y la XXXVIII respectivamente-: la primera comienza con la aleya del viaje nocturno, y en ambas se menciona a Moisés, pero también a David y a Salomón, con fuertes implicaciones con el templo judaico, a la vez que desarrollan el tema - recurrente en el Corán- del pueblo sordo a las advertencias de los profetas, y que recibe en consecuencia un castigo, lo cual reporta a la visión musulmana sobre los judíos alimentada por la tradición ulterior, e implicaría en última instancia una interpretación de la ruina del templo.

Vemos así al califa Omar manifestar la intención de iniciar un sitio de plegaria para el culto musulmán; de hecho, al marcar sus actos el final de la era de la quadra y el comienzo de la época del Haram resultaba un compromiso, dado que, para mostrar el cumplimiento de las profecías del Evangelio, los cristianos la mantenían convertida en un muladar. En un gesto no carente del sentido de lo notorio, si tomamos en cuenta que se trataba del jefe de un Estado cuyas fronteras se ensanchaban día con día, ${ }^{49}$ el califa comenzó él mismo a escombrar el espacio donde realizaría el rito, lo que constituía un acto simbólico

${ }^{48}$ Se trata de uno de los espacios situados al este de la cúpula de al-Aqsà; limita con el muro sur y es continuación del crucero, y conforman una suerte de anexos: jâmi ${ }^{\prime}$ al-arba'în -asamblea de "los cuarenta"-, más un mibrâb Zaqâriyâ al norte, lugares de devoción que pudieran ser indicios del emplazamiento original de la plegaria de Omar. R. W. Hamilton (The Structural History of the Aqsa Mosque. A Record of Archaeological Gleanings from Repairs of 1938-1942, Londres, Oxford University Press, 1949, frontispicio; e il. 7, p. 11), el cual considera su construcción tardía, posterior incluso a los mamelucos.

${ }^{49}$ Asimismo, Teófanes pone en boca de Sofronio los términos "abominación de la desolación sobre el lugar sagrado" refiriéndose a los actos de Omar sobre la quadra, como llevando a la construcción de un templo "pagano" (Abel, Histoire de 
notable. Los reportes coinciden en sugerir que la imagen de Omar dota al Haram de especial importancia, sin hacer referencia al Santo Sepulcro, sino a la voluntad de crear un santuario especial para los musulmanes.

La primera mezquita, al sur de la explanada, sería descrita por un obispo de nombre Arculfo, peregrino de las Galias, posterior a 670; alude a un lugar de oración musulmana en madera, de factura tosca, un extenso tejaván: "una casa de oración cuadrada, hecha con grandes trabes y tablones, sobre ruinas; una obra de baja calidad", ${ }^{50}$ identificable como la primitiva edificación de al-Aqsà. Los omeyas deciden sustituirla al construir un conjunto que ocupará la totalidad del espacio del Haram, donde al-Aqsà sigue funcionando como el mayor lugar de oración -aquel donde se pretende reunir a la comunidad entera, al-jâmi', la mezquita aljama-de Jerusalén; sólo más tarde la tradición popular identificará la roca como sitio de la ascensión del Profeta y el lugar de la plegaria del califa, de donde también proviene la calificación errónea de "mezquita de Omar" para el Domo. ${ }^{51}$

Al-Muqaddasî (siglo x) refiere que 'Abd al-Malik, quinto califa omeya, impresionado por la magnificencia de la Qumâ$\mathrm{ma}$-el Santo Sepulcro-, ${ }^{52}$ habría comenzado la construcción del Domo, y se la habría encargado a los maestros de obras de

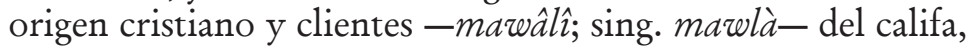

la Palestine..., op. cit., p. 399). La tarea de escombrar el sitio fue continuada a partir del día siguiente por una cuadrilla de esclavos.

${ }^{50}$ En la totalidad del relato, el recuerdo de la magnificencia del templo resalta el contraste con el pobre aspecto del edificio musulmán. Gil, $A$ History of Palestine, op. cit., p. 90. De acuerdo con Arculfo, se trataba de una construcción cuadrangular, de aspecto rudo y sin interés; según Ugo Monneret de Villard (Introduzzione allo studio dell'archeologia islamica. Le origine e il periodo Omayyade, Venecia-Roma, Istituto per la Collaborazione Culturale, 1968, p. 206), orientada hacia el este, lo cual sería dudoso, a menos que estuviera adosada al muro oriental, cosa poco probable.

${ }^{51} \mathrm{La}$ mezquita principal, donde se pretende que se reúna toda la comunidad, recibe la denominación de jâmi - asamblea-, en árabe; el término difícilmente se diferencia en las lenguas europeas, y para describirla se ha utilizado en diversos casos "mezquita del viernes", "mayor", "congregacional”, "aljama”, o aun "catedral”. La atribución a Omar de haber construido el Domo aparece tanto en tradiciones islámicas como en la cristiana de Teófanes y la judía de Simón bar Yohay. Gil, A History of Palestine, op. cit., p. 91.

${ }^{52}$ Literalmente, Qubbat al-Qumâma, "el Domo de la basura”, el término despectivo utilizado por los musulmanes para designar el Santo Sepulcro, denominado "la resurrección", al-Qiyâma. 
Rajâ' ibn Hayat y Yazîd ibn Salâm. ${ }^{53}$ Antes de comenzar le habrían propuesto el modelo in situ, y consultado a expertos en construcción. El autor señala la fama de las iglesias de Siria, por lo cual era necesario realizar una construcción de la que los musulmanes estuvieran orgullosos, e incluso las opacara. Los trabajos durarían cuatro años y consumirían el tributo agrícola de Egipto durante un septenato. Al mismo tiempo, la cólera de los cristianos nutrió el argumento de que los materiales utilizados provenían de iglesias. Esto parece un uso testado por el cronista Teófanes en su Cronografía:

Abimelec [sic, éste era el nombre que daba a 'Abd al-Malik] envió hombres para construir el "templo de La Meca" [... y se proponía tomar las columnas de Getsemaní - la iglesia de la Agonía- con ese ruin propósito, pero Sergio, su tesorero cristiano, le pidió no hacerlo, sugiriéndole, en cambio, pedir otras columnas a Constantinopla, pues el basiléos se las entregaría], cosa que fue hecha. ${ }^{54}$

En el relato de Arculfo acerca de la tosca edificación sobre la quadra se manifestaban rasgos de la actitud negativa tradicional del cristianismo, caracterizada por el empecinamiento contra la reconstrucción del templo, e identificaba con la "abominación de la desolación" cualquier edificio sobre la explanada, para reafirmar el dictamen de que el sitio se mantuviera desolado, algo cuya contravención incurría en implicaciones milenaristas. ${ }^{55}$ En este contexto es que podemos comprender su insistencia al criticar la basteza del oratorio musulmán, en contraste con la

${ }^{53}$ Hay divergencias en cuanto a los nombres de los alarifes, aunque todas las fuentes coinciden sobre su estatus clientelar. El primero era probablemente el contratista, y el segundo vendría secundado por su hijo, Bahâ' ibn Yazîd.

${ }^{54}$ Qâmûs, "sakhra". Cyril Mango, The Art of the Byzantine Empire, Nueva Jersey, Prentice Hall, 1972, p. 132. Resalta la denominación del Domo como "templo de La Meca”. La apropiación de materiales provenientes de iglesias se revela en el relato de al-Muqaddasî: para la construcción de la mezquita de Damasco, el califa Hishâm habría lanzado un ultimátum a los cristianos para que le entregaran unas hermosas columnas escondidas bajo la arena, a defecto de lo cual arrasarían la iglesia de San Jorge de Ludd (Lod) con el fin de obtener columnas del tipo adecuado (ibid., p. 185). Eutiquio incluso acusaba a al-Walîd, a quien reporta como constructor del Domo, de haber despojado de su techo una construcción eclesial, hoy no identificada, de Heliópolis (Ba albek), para ponerla sobre la Roca, lo cual, de ser cierto, habría sido la cúpula original.

${ }_{55}$ Jean Flori, Guerra santa, yihad, cruzada: violencia y religión en el cristianismo y el islam, Granada, Universidad de Granada-Universitat de València, 2004, p. 83. 
reconocida magnificencia del templo, con el que seguramente lo ligaba, además de compararlo con la suntuosidad de las basílicas e iglesias votivas.

En cambio, el hecho alcanzó comentarios favorables entre los judíos. Así, un manuscrito gaónico perteneciente a la biblioteca Bodleian de Oxford, afirma que "vendrá uno de los hijos de Cedar, $y$ un rey entre sus descendientes [...] va a reconstruir el templo del Dios eterno de Israel [...] y su nombre será 'Abd al-Malik ibn Marwân". ${ }^{56} \mathrm{La}$ alocución es reveladora de una actitud acorde con la voluntad de allegarse al nuevo ocupante por parte de los judíos de Siria ante la conquista musulmana, celebrándola como una liberación: gracias a ella, entre otras cosas, podrían volver a habitar la ciudad santa, ${ }^{57}$ pero a la vez operaban otros factores simbólicos en juego; entre ellos, la identificación con los nuevos conquistadores en su oposición al dogma de la trinidad de los cristianos, denostados además como opresores. Aun contemplando a los "hijos de Ismael" como un grupo con identidad distinta, los judíos celebraban su llegada con una visión milenarista, buscaban en los acontecimientos el cumplimiento de las profecías, ${ }^{58}$ y manifestaban un acerca-

${ }^{56}$ Citado por Myriam Rosen-Ayalon (The Early Islamic Monuments of alHaram al-Sharîf. An Iconographic Study, Jerusalén, The Hebrew University of Jerusalem, 1989, p. 62), de Israël Lévi, "Une apocalypse judéo-arabe", Revue des Etudes Juives, 69, 1914. Cedar - hebreo Qedar- es el nombre de uno de los hijos de Ismael (Génesis xxv: 13).

${ }^{57} \mathrm{El}$ acuerdo tenía como antecedente el concertado por el Profeta con los judíos de Tabûk, en el año 630. M. Gil (A History of Palestine, op. cit., pp. 67-74) realiza un estudio sobre ese retorno en las diversas fuentes, en especial las provenientes de los qaraítas. El acercamiento llegaría incluso a tomar la forma del faccionalismo en la profanación e incendio de iglesias, consideradas como ataques a la idolatría, por bandas de musulmanes y judíos, de lo que estos últimos serían además instigadores.

${ }^{58}$ M. Gil (ibid., p. 64) insiste en el hecho de que para los judíos no se trataba sino del predecesor del ungido, el mesías. Empero, las interpretaciones delatan su júbilo; así, en documentos de la literatura de midrash consta una interpretación de Números xxIv: 21 en que el reino de Ismael sustituye al depravado de Edom -Roma y Constantinopla, en este caso-, o bien de Isaías Xxi: 7, en que la opresión viene con el hombre que monta un asno -Jesús-, mientras que el que monta un camello porta la liberación (la interpretación usual del pasaje se refiere a eventos de la conquista por Ciro el Grande). En Tabarî aparece un judío de Damasco asegurando a Omar que los árabes bajo su mando matarían al "hijo de la abominación" —en árabe, al-dajjâl, la versión musulmana del Anticristo-. En los relatos judíos aparece incluso un "príncipe Abgar", un árabe que habría entregado su vida por desobedecer al tiránico Vespasiano, el cual le habría encomendado destruir el muro occidental. En contraste, los cronistas cristianos son abiertamente hostiles respecto a la conquista árabe, pues 
miento con el islam, un terreno fértil en el que se forjarían los relatos musulmanes, con incidencia en el estatus de Jerusalén dentro de la mentalidad mística y religiosa. Reacción que contrasta con la irritación resignada entre los cronistas cristianos, que atribuyen cierta identidad entre judíos y musulmanes, lo cual constituiría de cualquier modo un tema recurrente de la apologética cristiana en contra del islam, al condenarlo como una restauración de la "antigua alianza" y la vieja ley. ${ }^{59}$

En este contexto de condena acerca de cualquier edificio sobre la explanada se encuadra una narración legendaria que cita el mismo Teófanes, quien continúa una tradición ya cristalizada: así, refiere que los primeros trabajos de "reconstrucción del templo" habían sido inútiles, y se derrumbaban los muros iniciales, hasta que el poder consultó a los judíos, quienes advirtieron que tal situación continuaría mientras se mantuviera en pie una cruz erigida sobre el Monte de los Olivos. Apenas el califa ordenara derribarla, se hizo posible llevar a cabo la construcción de manera normal; a lo que agrega el cronista que "por esa razón han derribado tantas cruces los enemigos de Cristo". ${ }^{60}$ El relato, además de hacer resaltar el valor milagroso del símbolo cristiano, transluce la colaboración entre judíos y musulmanes, y la situación real que lo motiva: la destrucción de imágenes en la confrontación entre formas de fe monoteísta en ese momento. El cronista georgiano del siglo $\mathrm{x}$, Teodoro, describe también la situación de acuerdo con la visión tradicional en muchos aspectos:

Los sarracenos ateos entraron en la Ciudad Santa de Cristo Nuestro Señor, Jerusalén, con el permiso de Dios, como castigo a nuestra inconmensurable negligencia, y acudieron al lugar llamado el Capitolio llevando hombres, algunos por la fuerza, otros libremente, con el fin

dicen que llegan "con el Corán en una mano y la espada en la otra” (Philip K. Hitti, History of Syria including Lebanon and Palestine, Londres-Nueva York, MacMillanSaint Martin Press, 1957, p. 420).

${ }^{59} \mathrm{La}$ asimilación de los árabes con los judíos se muestra en documentos como el Sueño de Heraclio, que habría desatado la persecución a los primeros cuando le profetizaron a Heraclio que un "pueblo de circuncisos" le arrancaría el imperio.

${ }^{60}$ André Grabar (La iconoclastia bizantina, Madrid, Akal, 1998, pp. 126 y ss.) cita que el judío Tessarakontapechys [sic] vaticinó al noveno califa omeya, Yazîd II, un reino de cuarenta años, a condición de que destruyera los iconos de las iglesias, algo que comenzó a hacer, a pesar de lo cual su reinado fue breve. 
de limpiar el lugar y edificar esa maldita cosa destinada a sus plegarias que ellos llaman midzgita [sic]. ${ }^{.1}$

Los ejemplos de relato condenatorio proliferan sin variar la tónica, y aseguran que los habitantes cristianos de Jerusalén se veían aterrados por la espantosa gritería nocturna de los demonios ocupados en la faena de despejar el sitio, previa a la construcción del Haram, que obviamente colaboraban en la obra de sus aliados, los musulmanes, quienes habían introducido cuadrillas de trabajadores egipcios, aunque diurnos. ${ }^{62}$

Al advenimiento de los omeyas, Jerusalén alcanza un nuevo realce con la proclamación califal de $\mathrm{Mu}$ ê̂wiya, que Tabarî menciona apenas. En cambio, los cronistas cristianos insisten en el hecho de que "el rey" ni siquiera porta corona, lo que pretende evidenciar una deficiencia, pero a la vez dar una muestra más de la falsa humildad que ya Sofronio había atribuido a los nuevos conquistadores, buscando una vez más el contraste con la entrada de Heraclio a la ciudad portando descalzo la cruz. ${ }^{63}$

En gran parte como respuesta, el imaginario musulmán teje nuevas leyendas al respecto, para contraponerse a las elaboradas por los cristianos; incluso al asumir la idea de que se habían hecho merecedores de perder el santuario al ser culpables de profanar el sitio del templo, para agregar que, como castigo, la providencia les había impedido reconstruirlo - lo cual

${ }^{61}$ El texto agrega un ejemplo de tintes moralizantes: "Entre esos hombres se encontraba Juan, archidiácono de San Teodoro Mártir, porque era de su oficio tallador de mármol [...] Cuando el bienaventurado santo Sofronio [...] le pidió, como un padre y pastor razonable del rebaño que Dios le confiara, no profanar sus manos y apartarse de empresa tan abominable" -la perdición del personaje ilustrará al final el castigo a su desobediencia- (Bernard Flusin, "L’Esplanade du Temple à l'arrivée des Arabes, d'après des récits byzantins", en Julian Raby y Jeremy Johns [eds.], Bayt al-Maqdis. 'Abd al-Malik's Jerusalem, Oxford-Nueva York, Oxford University Press, 1992, p. 21).

${ }^{62}$ Conseja referida por Anastasio del Sinaí, en sus Relatos para fortalecer la fe (apud Peter Brown, El primer milenio del cristianismo occidental, Barcelona, Crítica, 1997, p. 167), quien apunta el hecho de que, para el monje cristiano, reconstruir el templo constituía una aberración blasfema. B. Flusin (“L’Esplanade du Temple...", $o p$. cit.) reproduce el texto original griego y concluye que se trata de maniobras para escombrar el sitio del Domo.

${ }^{63}$ La ausencia de ese símbolo de realeza puede más bien haber sido una concesión hacia la oposición musulmana, que criticaba a los omeyas por haber transformado la institución califal en una monarquía. 
resulta una interpretación excesiva, pues se trata de algo que al parecer ningún gobernante cristiano pretendió realizar-, lo cual aducían como prueba de la predilección divina por el islam, conforme al modelo de las leyendas judías que los musulmanes absorbieron, al grado de que muchos elementos de las isrấîliyyât $t^{64}$ se encuentran en el género literario de qisas al anbiy $\hat{a}$ ', o historias de los profetas, y en los relatos de fadâ'il, que enumeran las excelencias de una ciudad o región determinada, donde también se entretejen elementos cristianos.

El conjunto del Haram incluye en la época omeya tanto el Domo como al-Aqsà, aunque excede el área de la explanada al incluir también el palacio edificado al sur. Al respecto, una de las denominaciones de Jerusalén utilizadas por al-Muqaddasî es la de al-Balat - que proviene del latín palatium - ${ }^{65}$ Sin embargo, para los musulmanes, la conformación del Haram como santuario excede muy pronto el significado dinástico que los omeyas pretendieran darle al sitio. En ello, las leyendas sobre la roca como axis mundi adquirirían importancia en la formulación del relato del viaje nocturno del Profeta, dividido en el traslado de La Meca a Jerusalén, denominado al-isrâ', sobre la cabalgadura fantástica, al-Burâq, y una vez sobre la mezquita remota -alAqsà-, el Haram, el ascenso vertical hacia el último cielo: al-mi râj. De esta manera, renueva la concepción judaica, la cual identificaba la roca como Eben shetiyyá, aquella de la fundación del mundo y la creación de Adán, para representar el omfalós. ${ }^{66}$

Al sobrevenir el cambio dinástico a favor de los abasíes, en 750 , mientras el centro político bascula hacia Bagdad, las

${ }^{64}$ Expresamente una leyenda, de acuerdo con la cual los cristianos habrían bañado el lugar con los menstruos - un líquido impuro en particular- de las mujeres de Constantinopla, aparece tanto en registros musulmanes como en la obra del qaraíta Salmón ben Yeruhîm, natural de Jerusalén, que vivió en el siglo x (Heribert Busse, "Jerusalem in the Story of Muhammad's Night Journey and Ascension", Jerusalem Studies in Arabic and Islam, vol. 14, 1991, p. 451; Gil, A History of Palestine, op. cit., p. 67).

${ }_{65}^{65}$ Buhl, "al-Kuds", op. cit., p. 1094.

${ }^{66}$ Jerusalén y la roca se denominan justamente "ombligo de la tierra" - tabbur ha-áretz- por la tradición a partir de Ezequiel xxxviII: 12. La roca es lo primero creado y tapona la boca del abismo primordial -tehom, Génesis I: 2-, lo que implica su función de comunicar con los cielos y el inframundo: "Jerusalem in the Aggadah", en C. Bezalel Roth (ed.), Encyclopredia Judaica, op. cit., p. 1558; Mircea Eliade y Lawrence E. Sullivan, "Center of the World", en Mircea Eliade et al. (eds.), The Encyclopedia of Religion, Nueva York, McMillan, 1986, t. III, p. 167. 
construcciones sobre el Haram no parecen haber sufrido profanación ni destrucción considerable, como otras obras de los omeyas. Ciertamente, pueden haber sufrido cierta incuria que ya venía desde antes, pero ha sido registrada su reparación por los nuevos gobernantes; así, el tercer califa abasí, al-Mahdî, afirmaba que los omeyas se le habían adelantado en la edificación del Domo y la mezquita de Damasco. A lo anterior se agrega el intento del séptimo califa abasí, al-Ma'mûn (r. 813-833; 198-214 h.), de atribuirse su construcción al ordenar alterar un fragmento de la dedicatoria del edificio y sustituir el nombre de 'Abd al-Malik por el suyo propio, sin que fuese modificada la fecha original, el año 72 de la hégira, muy anterior, pues equivale a $692 .{ }^{67}$

Más adelante se vio a la dinastía shí́ta de los fatimidas, rival de los abasíes, que desde El Cairo se apoderan de Jerusalén bajo al-Mu izz, su cuarto califa, y contribuyen a remozar las estructuras del Haram, en especial al-Aqsà, la mezquita aljama, a partir de 1022, con lo cual asumían el patronazgo del lugar para acrecentar su propio prestigio.

\section{Conclusiones}

En el caso de la historia previa del Haram hasta su construcción por el islam como semióforo, es decir, como una obra que funciona a la vez como referencia simbólica, sería importante retener tres ejes fundamentales, que son a la vez temas merecedores de investigación por sí mismos.

Por una parte, el dominio de memoria está marcado por el predominio de las expectativas milenaristas relacionadas con la desaparición del templo y el interés del cristianismo en la ostensible ruina del lugar, lo cual llevó a la asimilación con éste de cualquier construcción que se realizara sobre la explanada, tanto entre cristianos como judíos. En las crónicas de los au-

${ }^{67} \mathrm{La}$ permanencia de la fecha original delata un descuido que vuelve la falsificación evidente; sin embargo, M. Van Berchem consideraba el acto una "toma de posesión simbólica" del monumento, "el desvío del prestigio religioso y político en su provecho", comparable con una afirmación de patronazgo (Grabar, The Shape of the Holy, op. cit., p. 64). 
tores árabes, al establecer un sitio musulmán, vemos al califa Omar no sólo en búsqueda del mibrâb Dâwûd, sino también entrar en juego con este tipo de especulaciones.

Sin embargo, la construcción del Haram renueva un rasgo cultural común al área del Medio Oriente antiguo: el templo salomónico se construyó en asociación con el palacio real, del cual constituía un anexo, lo que era ya conocido desde mediados del siglo XIX. Tal asociación puede observarse en la presencia de un palacio al sur del Haram, durante el califato de los omeyas, y la identificación del sitio con la dinastía en el poder, algo que implica la renovación de una continuidad que parecería interrumpida.

Los musulmanes adoptan la concepción del Haram como santuario, hasta conformar los relatos de ascensión del Profeta, traslado vertical que reafirma el concepto de su emplazamiento como axis mundi, lo que se superpone en la mentalidad musulmana al significado particular dinástico que los omeyas pretendieran darle al sitio.

Dirección institucional del autor:

Centro de Estudios de Asia y África

El Colegio de México

Camino al Ajusco 20

Pedregal de Santa Teresa

10740, Ciudad de México

\section{Bibliografía}

ABel, Félix M., Histoire de la Palestine depuis la conquête d'Alexandre jusqu'à l'invasion arabe, 2 vols., París, Lecoffre, 1952.

Armstrong, Karen, Historia de Jerusalén. Una ciudad y tres religiones, Barcelona, Paidós, 2005.

Auerbach, Jacob, "Western Wall”, en C. Bezalel Roth (ed.), Encyclopcedia Judaica, Jerusalén, Keter, 1972, vol. XvI, pp. 467-472.

Avr-YonAH, Michael, “Jerusalem. History”, en C. Bezalel Roth (ed.), Encyclopeedia Judaica, Jerusalén, Keter, 1972, vol. IX, pp. 1378-1408. BAERT, Barbara, "Héraclius, l'exaltation de la Croix et le MontSaint-Michel au XI ${ }^{\mathrm{e}}$ siècle. Une lecture attentive du ms. 641 de la 
Pierpoint Morgan Library à New York", Cabiers de Civilization Médiévale, vol. LI, núm. 201, 2008, pp. 3-20.

BEN-Dov, Meir, Historical Atlas of Jerusalem, Jerusalén, Continuum, 2002.

Ben-Sasson, Haim Hillel, "Messianic Movements", en C. Bezalel Roth (ed.), Encyclopcedia Judaica, Jerusalén, Keter, 1972, vol. XI, pp. 418-442.

Biddle, Martin (ed.), The Church of the Holy Sepulchre, Nueva York, Rizzoli, 2000.

BiguzZI, Giancarlo, "Yo destruiré este templo": El templo y el judaísmo en el Evangelio de Marcos, Córdoba-Madrid, Ediciones El Almendro, 1992.

BRown, Peter, El primer milenio del cristianismo occidental, Barcelona, Crítica, 1997.

BuHL, Friedrich, “al-Kuds”, en M. Th. Houtsma et al., First Encyclopaedia of Islam, Leiden-Nueva York, E. J. Brill, 1993, vol. IV, pp. 1094-1104.

BusinK, Th. A., Der Tempel von Jerusalem von Salomo bis Herodes: Eine archäeologisch-historische Studie unter Berucksichtigung des Westsemitisches Tempelbaus, Leiden, E. J. Brill, 1979.

Busse, Heribert, "Jerusalem in the Story of Muhammad's Night Journey and Ascension", Jerusalem Studies in Arabic and Islam, vol. 14, 1991, pp. 1-40.

Caseau, Béatrice, "Sacred Landscapes", en G. W. Bowersock, P. Brower y O. Grabar (eds.), Late Antiquity. A Guide to the Postclassical World, Cambridge-Londres, Harvard University Press, 1999.

Creswell, K. A. C., Early Muslim Architecture, Nueva York, Hacker, 1979 (edición corregida, 1969), t. I, vol. 1.

Crone, Patricia, "Islam, Judeo-Christianity and Byzantine Iconoclasm", Jerusalem Studies in Arabic and Islam, vol. 2, 1980, pp. 59-95.

EliADE, Mircea y Lawrence E. Sullivan, "Center of the World", en Mircea Eliade et al. (eds.), The Encyclopedia of Religion, Nueva York, McMillan, 1986, t. III, pp. 166-171.

Every, George, Christian Mythology, Londres, Hamlyn, 1970.

FAHD, Toufic, "Talbiya”, en H. A. R. Gibb et al., Encyclopaedia of Islam / Encyclopédie de l'islam, Leiden, E. J. Brill, 1960-2002, vol. X, p. 160.

FÉHÉrvary, G., "Mihrâb", en H. A. R. Gibb et al., Encyclopaedia of Islam / Encyclopédie de l'islam, Leiden, E. J. Brill, 1960-2002, vol. vII, pp. 7-15.

FINKELSTEIN, Israel y Asher Silbermann, David y Salomón: en busca de 
los reyes sagrados de la Biblia y de las raíces de la tradición occidental, Madrid, Siglo XXI, 2006.

Flavio Josefo, Antigüedades judías, 2 vols., ed. José Vara Donado, Madrid, Akal, 1997.

FLORI, Jean, Guerra santa, yihad, cruzada: violencia y religión en el cristianismo y el islam, Granada, Universidad de Granada-Universitat de València, 2004.

Fuusin, Bernard, "L'Esplanade du Temple à l'arrivée des Arabes, d'après des récits byzantins", en Julian Raby y Jeremy Johns (eds.), Bayt al-Maqdis. 'Abd al-Malik's Jerusalem, Oxford-Nueva York, Oxford University Press, 1992, pp. 17-31.

Foucault, Michel, La arqueología del saber, México-Buenos AiresMadrid, Siglo XXI, 1970.

Frazer, James George, El folklore en el antiguo testamento, México, Fondo de Cultura Económica, 1981.

GANschow, Thomas, "Aelia Capitolina”, en Lexicon Iconographicum Mythologiae Classicae, Supplementum, Zúrich-Düsseldorf, Artemis, 1997, pp. 504-506.

Gerard, André-Marie (ed.), Dictionnaire de la Bible, París, Robert Laffont, 1989.

GIL, Moshe, A History of Palestine, 634-1099, Cambridge-Nueva York, Cambridge University Press, 1992.

Gold, Victor Roland, "The Mosaic Map of Madeba”, Biblical Archaeologist, vol. XXI, núm. 3, 1958, pp. 50-71.

Grabar, André, La iconoclastia bizantina, Madrid, Akal, 1998.

Grabar, Oleg, The Shape of the Holy. Early Islamic Jerusalem, Princeton, Princeton University Press, 1996.

Hamilton, R. W., The Structural History of the Aqsa Mosque. A Record of Archaeological Gleanings from Repairs of 1938-1942, Londres, Oxford University Press, 1949.

Hiтti, Philip K., History of Syria including Lebanon and Palestine, Londres-Nueva York, MacMillan-Saint Martin Press, 1957.

Levinas, Emmanuel, Más allá del versículo: lecturas y discursos talmúdicos, Buenos Aires, Lilmod, 2006.

Lods, Adolphe, Israël des origines jusqu'au milieu du vII siècle, París, La Renaissance du Livre, 1932.

Mango, Cyril, The Art of the Byzantine Empire, Nueva Jersey, Prentice Hall, 1972.

MARKsChIES, Cristoph, Estructuras del cristianismo antiguo. Un viaje entre mundos, Madrid, Siglo XXI, 2001.

Martínez Delgado, José, "Las versiones árabes de La Destrucción de Jerusalén por los persas (614, d.C.)”, 'Ilu. Revista de Ciencias de las Religiones, vol. XI, 2006, pp. 179-204. 
Momigliano, Arnaldo, Ensayos de historiografía antigua y moderna, México, Fondo de Cultura Económica, 1993.

MonNeret DE VILlard, Ugo, Introduzzione allo studio dell'archeologia islamica. Le origine e il periodo Omayyade, Venecia-Roma, Istituto per la Collaborazione Culturale, 1968.

MOURRET, Fernand, Histoire générale de l'église, t. II : Les pères de l'église, París, Bloud \& Gay, 1928.

Notн, Martin, Histoire d'Israël. Des origines à la destruction du Temple, París, Payot, 1985.

Pomian, Krzysztof, Sobre la bistoria, Madrid, Cátedra, 2007.

RAPPOPORT, Angelo, Ancient Israel Myths and Legends, 3 vols., Nueva York, Bonanza, 1987.

RÉAU, Louis, Iconografía del arte cristiano, 2 ts. en 6 vols., Barcelona, Ediciones del Serbal, 1995-1999.

Renan, Ernest, Euvres complètes, 8 vols., ed. Henriette Psichari, París, Calmann Lévy, 1947.

Rives, James, "Flavian Religious Policy and the Destruction of the Jewish Temple", en J. Edmonson et al. (eds.), Flavius Josephus and Flavian Rome, Oxford-Nueva York, Oxford University Press, 2005, pp. 145-166.

RoberTson SMith, W., Religion of the Semites with a New Introduction by Robert $A$. Segal, Nueva Brunswick-Londres, Transaction Books, 2012 (facsímil de la edición de 1892).

Rosen-Ayalon, Myriam, The Early Islamic Monuments of al-Haram al-Sharîf. An Iconographic Study, Jerusalén, The Hebrew University of Jerusalem, 1989.

RothкоF, Aaron, "Solomon. In the Aggadah", en C. Bezalel Roth (ed.), Encyclopcedia Judaica, Jerusalén, Keter, 1972, vol. xv, pp. 105-108.

Stemberger, Günter, El judaísmo clásico. Cultura e historia del período rabinico, Madrid, Trotta, 2011.

Torres, Juana, "La ocupación de espacios sagrados como fuente de conflicto entre paganos y cristianos", 'Ilu. Revista de Ciencias de las Religiones, Anejo XVIII, 2007, pp. 85-98.

Vaux, Roland de, Les institutions de l'Ancient Testament, París, Les Éditions du Cerf, 1960, t. II.

WeINFELd, Eduardo et al. (eds.), Enciclopedia Judaica Castellana, México, Editorial Enciclopedia Judaica Castellana, 1950, t. vIII. WeInfeld, M., "Cult Centralization in Israel in the Light of a NeoBabylonian Analogy", Journal of Near Eastern Studies, vol. xxIII, núm. 3, julio de 1964, pp. 202-212. 
